\title{
The Radio Occultation Experiment aboard CHAMP: Operational Data Analysis and Validation of Vertical Atmospheric Profiles
}

\author{
Jens WICKERT, Torsten SCHMIDT, Georg BEYERLE, Rolf KÖNIG, \\ Christoph REIGBER
}

GeoForschungsZentrum Potsdam (GFZ), Department Geodesy and Remote Sensing, Potsdam, Germany

and

Norbert JAKOWSKI

German Aerospace Center (DLR), Institute of Communications and Navigation, Neustrelitz, Germany

(Manuscript received 7 April 2003, in revised form 26 September 2003)

\begin{abstract}
The operational data analysis of the GPS radio occultation experiment aboard the German CHAMP (CHAllenging Minisatellite Payload) satellite mission is described. Continuous Near-Real-Time processing with average time delay of $\sim 5$ hours between measurement and provision of analysis results is demonstrated. A delay of less than 3 hours is reached for individual events. This is made possible by using an operationally operated ground infrastructure, consisting of a polar downlink station, a globally distributed fiducial GPS ground network, a precise orbit determination facility, an automated occultation processing system and an advanced data center (the Information System and Data Center at GFZ, ISDC). The infrastructure was installed within the CHAMP and the German GPS Atmosphere Sounding Project (GASP). More than 120,000 globally distributed occultation measurements were automatically analysed during 2001 and 2002. A set of $\sim 46,000$ vertical profiles of refractivity, temperature and water vapor is validated with meteorological analyses from the European Centre for Medium-Range Weather Forecasts (ECMWF) and data from the global radiosonde network. The mean temperature bias in relation to the analyses is less then $0.4 \mathrm{~K}$ between 10 and $35 \mathrm{~km}$, the mean deviation of the refractivity is $<0.5 \%$. A height dependent standard deviation of $\sim 1 \mathrm{~K}$ at $10 \mathrm{~km}$ and $\sim 2 \mathrm{~K}$ at $30 \mathrm{~km}$ is observed. This result is confirmed by comparing $\sim 6,000$ CHAMP occultations with corresponding radiosonde measurements. A negative bias of the refractivity in relation to the analyses up to $\sim 5 \%$ in the Tropics is found in the lower troposphere. It corresponds to mean meridional dry biases of the specific humidity up to $\sim 30 \%$. It is shown, that the application of a heuristic retrieval method, based on the Canonical Transform method and the sliding spectral approach, reduces the refractivity bias on average by a factor of $\sim 2$. The corresponding bias in the specific humidity is reduced by a factor of $\sim 3$. In mid-latitudes almost no more refractivity bias out of the planetary boundary layer is observed. This is shown by a comparison of
\end{abstract}

Corresponding author: Jens Wickert, Geo-

ForschungsZentrum Potsdam (GFZ), Department

Geodesy \& Remote Sensing, Telegrafenberg,

14473 Potsdam, Germany.

E-mail: jens.wickert@gfz-potsdam.de

(C) 2004, Meteorological Society of Japan 
CHAMP refractivity and water vapor profiles with radiosonde data. More than 50,000 globally distributed electron density profiles were automatically derived during 2001/2002. A validation study including 1,004 comparisons with corresponding ionosonde data yields a bias of $0.18 \mathrm{MHz}$ and $13.4 \mathrm{~km}$ for foF2 and hmF2 respectively. The standard deviation is $1.28 \mathrm{MHz}$ (foF2) and $46.8 \mathrm{~km}$ (hmF2).

\section{Introduction}

The German geoscience satellite CHAMP, was launched on July 15, 2000 (Reigber et al. 2003a) and is in orbit for about 3 years as of mid 2003. The measurements of CHAMP are used to determine Earth's gravity (e.g., Reigber et al. 2003b) and magnetic field (e.g., Maus et al. 2002) and to derive precise information about the vertical refractivity, temperature, humidity and electron density distribution on a global scale using the innovative GPS Radio Occultation (GPS RO) technique (Jakowski et al. 2002b; Wickert et al. 2001a). The properties of this calibration-free atmosphere limb sounding technique (e.g., all-weather-capability, high accuracy and high vertical resolution) offer great potential for atmospheric and ionospheric research, improvement of numerical weather forecasts, space weather monitoring and climate change detection (e.g., Anthes et al. 2000; Hajj et al. 2000; Kuo et al. 2000; Kursinski et al. 1997). GPS radio occultation was pioneered

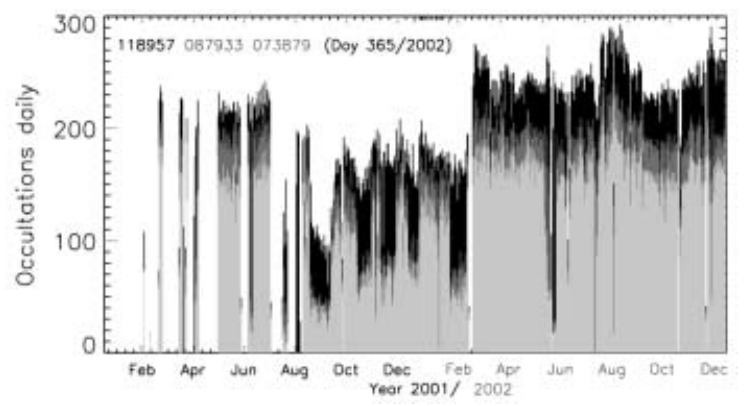

Fig. 1. Number of daily CHAMP atmospheric occultations (duration $>20 \mathrm{~s}$ ) for 2001 and 2002. The total height of the columns corresponds to the number of daily measurements. The black and dark grey color indicate occultations with calibration failure or insufficient data quality, respectively. The height of the light gray columns corresponds to the number of quality checked vertical atmospheric profiles provided to the CHAMP data center at GFZ. by the U.S. American GPS/MET (GPS/Meteorology)_Experiment (Rocken et al. 1997; Ware et al. 1996). CHAMP, together with the U.S.Argentinean SAC-C satellite, launched on November 21, 2000, succeeds GPS/MET (see e.g., Hajj et al. 2003).

Simultaneously with the realization of the CHAMP mission the HGF strategy funds (German's Helmholtz Association's instrument of competition) project GASP (GPS Atmosphere Sounding Project, 1999-2002, Reigber et al. 1998) was performed. The project was initiated to establish ground and space based GPS remote sensing techniques and their application in Germany. GASP was a project of the HGF research centers AWI (Alfred-WegenerInstitut für Polar- und Meeresforschung), DLR (Deutsches Zentrum für Luft- und Raumfahrt) and GKSS with GFZ as the project leading institution. The main project goals were: installation of an infrastructure for the operational provision of space- and ground-based GPS atmospheric data and the assessment of their value for applications in atmospheric research and weather forecast.

Here we focus on the operational analysis of the space-based data from CHAMP. The status

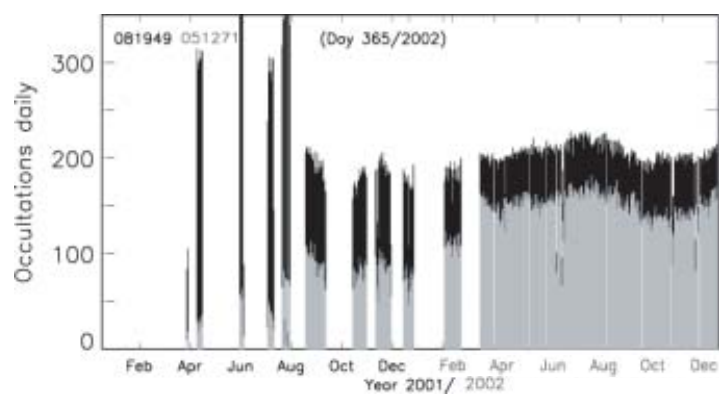

Fig. 2. Number of daily ionosphere occultations for 2002 (dark columns). The height of the grey columns corresponds to the number of vertical electron density profiles successfully retrieved by DLR Neustrelitz from ionospheric radio occultation measurements. 


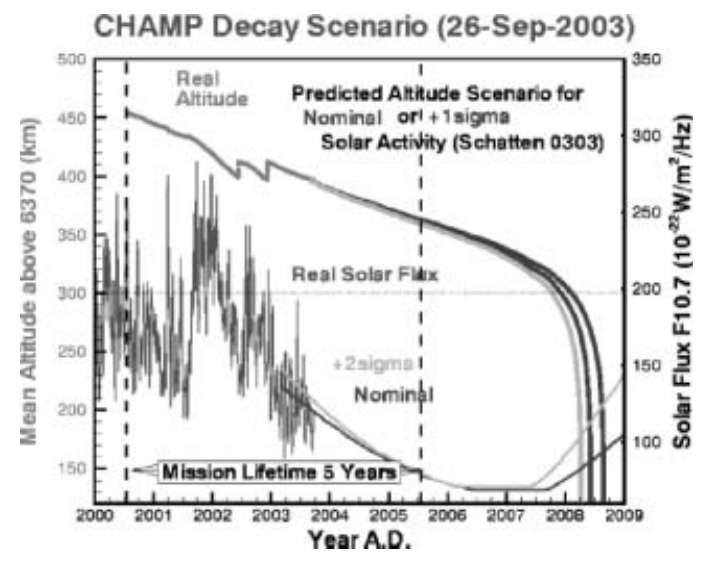

Fig. 3. Predicted altitude scenario for the CHAMP mission (as of September 2003). The scenario strongly depends on the real solar activity, which cannot be completely simulated in advance. Two manoeuvres with orbit lifting $(\sim 20 \mathrm{~km})$ have been successfully carried out on June 9 and December 10, 2002. Currently a lifetime (mean altitude above $\sim 300 \mathrm{~km}$ ) until late 2007 is expected (nominal).

of the radio occultation experiment is briefly reviewed and the operational occultation data analysis is characterized. The time delay between measurement and provision of analysis results is investigated with respect to the World Meteorological Organization's (WMO) requirements for the use of satellite based data in Numerical Weather Prediction (NWP, WMO TD No. 913, SAT-21, 28/9/1998), which for NWP demands a maximum latency of 1-4 h (global prediction) and $0.5-2.0 \mathrm{~h}$ (regional) respectively between measurement and provision of analysis results. Independent atmospheric/ ionospheric data sets (meteorological analyses from ECMWF, radiosondes and ionosondes) are used to validate the quality of the operational analysis results.

\section{Status of the CHAMP RO experiment}

CHAMP's GPS radio occultation experiment was activated on February 11, 2001, when 7 occultation measurements during an one hour period were recorded by the GPS receiver (Jet Propulsion Laboratory's "Blackjack") onboard the satellite (Wickert et al. 2001a). Since then within 578 days in 2001 (220) and 2002 (358) a total of 118,066 occultations (tracking of occulting and referencing GPS satellites in parallel $\geq 20 \mathrm{~s}$ ) were recorded. The calibration of the atmospheric excess phase was successful for 86,779 measurements (73.5\%). 72,798 vertical profiles of atmospheric parameters $(83.9 \%$ of the excess phases) passed the automatic quality check (Fig. 1).

The first ionospheric radio occultations were recorded on April 11, 2001 (Jakowski et al. $2002 b$ ). In total 81,949 measurements were recorded during 2001 and 2002; 51,217 electron density profiles were derived (Fig. 2).

After a flight-receiver software update on March 10, 2002 continuously on average about 260 atmosphere and 200 ionosphere daily events were recorded (Figs. 1 and 2). Since the CHAMP mission is currently expected to last until late 2007 (Fig. 3), an unprecedented longterm-set of GPS occultation data is anticipated.

\section{Infrastructure for GPS occultation data analysis}

The infrastructure for the GPS radio occultation experiment was installed within the frame-

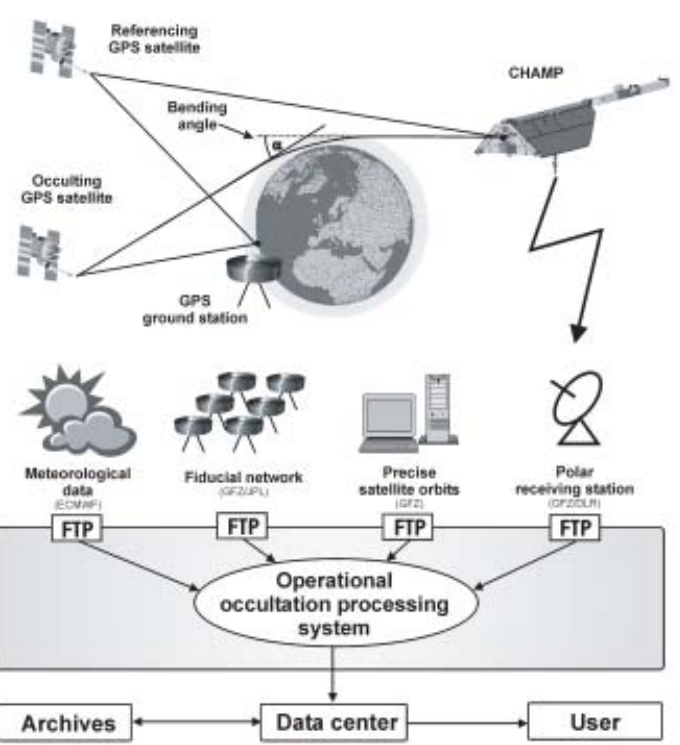

Fig. 4. Overview of the operational infrastructure for measurements, data reception, transfer, analysis and distribution of CHAMP's GPS radio occultation experiment (adapted from Wickert, 2002). 
work of the CHAMP mission and the GASP project (see Chap. 1).

The main components of the operational infrastructure for data generation, transfer, analysis and archiving are: the GPS receiver onboard the CHAMP satellite (provided by Jet Propulsion Laboratory, JPL) and the ground segment (see Fig. 4). It consists of the near polar downlink station at $\mathrm{Ny}$ Ålesund, Spitsbergen $\left(79.0^{\circ} \mathrm{N}, 11.5^{\circ} \mathrm{E}\right)$, the fiducial GPS ground network ("High rate and low latency network", currently consisting of about 40 stations, see e.g., Wickert et al. 2004/2001b; Galas et al. 2001), the Ultra rapid Precise Orbit Determination facility (König et al. 2003/2002), the operational analysis system for GPS occultation and ground data (e.g., Wickert et al. 2001a) and, for archiving and distribution, the CHAMP Information System and Data Center. A second downlink station at DLR Neustrelitz, Germany $\left(53.1^{\circ} \mathrm{N}, 13.1^{\circ} \mathrm{E}\right)$ serves as backup. The GPS ground network is operated in cooperation between GFZ and JPL, the other components are maintained by GFZ.

\section{Data analysis}

\subsection{Atmospheric excess phase calibration}

A double difference technique is used for the calibration of the atmospheric excess phase to correct for satellite clock errors. GPS measurements $(50 \mathrm{~Hz}$ precise phases L1 and L2) from the occulting and a reference GPS satellites are combined with simultaneously recorded GPS ground station data from the fiducial network (see also Fig. 4). Details of the excess phase calibration are given e.g., by Hajj et al. (2002), Wickert (2002), and Schreiner et al. (1998). Precise GPS and CHAMP ephemeris are necessary to correct for the relative motion of the satellites. These data are operationally provided by GFZ's precise orbit determination facility (König et al. 2003/2002).

The termination of the Selective Availability (SA) mode of the GPS (resulting in reduced amplitude of GPS clock variations; see e.g., Wickert et al. 2002) on May 2, 2000, 04:05 UTC had positive consequences for the excess phase calibration, which for first time were realized by the analysis of CHAMP's occultation data.

One profit is a possible reduction of the GPS ground station acquisition rate for double difference occultation processing from the stan- dard $1 \mathrm{~Hz}$ down to $1 / 30 \mathrm{~Hz}$ (standard acquisition rate of the International GPS Service (IGS) ground station network) without significant loss of vertical profile quality (Wickert et al. 2004, 2003). This fact is favourable for the data transfer and processing. The GPS ground data have the major part in the input data for the occultation processing. For a network of e.g., $\sim 25$ stations the daily amount is $\sim 1$ Gbyte, if $1 \mathrm{~Hz}$ data are used (more than $\sim 90 \%$ of the total input data amount). This can be significantly minimized using reduced acquisition rates.

Another advantage is the feasibility of the application of space-based single difference techniques for precise GPS occultation processing, which was demonstrated by Wickert et al. (2002). The author's results suggested that in result of the termination of SA the application of a space-based single difference technique provides nearly identical refractivity and temperature profiles compared to profiles processed using double differencing. This would not only significantly simplify the occultation processing system (no more direct use of ground station data), but also entirely avoid measurement error contributions from ground-to-satellite links (e.g., phase path noise, uncorrected ionosphere/troposphere or multipath at the ground station sites).

\subsection{Derivation of vertical neutral atmospheric profiles}

Vertical profiles of atmospheric refractivity are derived from atmospheric excess phase using the geometrical optics (GO) approximation and the Abel inversion technique (see e.g., Steiner et al. 1999). An algorithm, described by Sokolovskiy and Hunt (1996), is applied for the optimization of the bending angles using the MSISE-90 climatology (Hedin 1991). For dry air, the density profiles are calculated using the known relationship between density and refractivity. Temperatures ("dry" temperatures) are obtained from the hydrostatic equation and the ideal gas law. Water vapor profiles are derived applying an iterative method described by Gorbunov and Sokolovskiy (1993) using 6 hourly operational global weather analyses from ECMWF (see e.g., Marquardt et al. 2001). The complete occultation analysis is overviewed by Wickert et al. (2001a), details are 
given by Wickert (2002). Several modifications of the analysis software were performed since the first measurements and resulted in a new version of analysis results (version 004), which is provided since December 2002. Major modifications are: use of an empiric Doppler model for plausibility control of L1 and L2 data in the lower troposphere (for details see Hajj et al. 2002); use of ECMWF data for the initialisation of the hydrostatic equation at $43 \mathrm{~km}$ (one atmospheric scale height above the highest data point provided) and relation of the geometrical heights to the EGM96 geoid (Lemoine et al. 1998). The ECMWF data are also used for the quality control. A maximum deviation of the CHAMP relative refractivity in relation to the analyses data of $10 \%$ is allowed. In the lower troposphere the profiles are cut-off, when the deviation is beyond this limit. A heuristic retrieval method (CTss, Beyerle et al. 2003b) based on the Canonical Transform (CT) technique (e.g., Gorbunov 2002) and the sliding spectral (ss) approach (Sokolovskiy 2001) is found to reduce the lower tropospheric refractivity bias (e.g., Ao et al. 2003) by more than a factor of two (see Chap. 7.2). It is not yet applied to the operational data analysis. Another method of wave optics based occultation data analysis is the radioholographic approach (see e.g., Paveljev et al. 1996 or Hocke et al. 1999).

\subsection{Derivation of vertical electron density profiles}

A tomographic approach was established that uses spherical volume shells with constant electron density (e.g., Jakowski 1999). Differential GPS phase measurements provide the total electron content along the ray path as a summation over the path integral in the different shells. The discretization of the ray paths has the advantage that additional information from external sources such as peak electron densities or vertical TEC can easily be included in the reconstruction of the electron density profile. This advantage is currently not being used for the operational data analysis.

Since the geometric path length through the different layers can easily be determined, the electron density of different shells is then directly computed from the $1 \mathrm{~Hz}$ measurements starting with the uppermost layer down to the bottom of the ionosphere in a recursive way.
Because the rather low orbit height of CHAMP ( $\sim 400 \mathrm{~km}$, see Fig. 3, close to the peak density height of the F2 Layer), special care is needed to define the initial TEC before starting the retrieval. Various possibilities for using topside ionosphere/plasmasphere models have been tested for that purpose (Jakowski et al. 2002a).

\section{Operational data analysis}

A modular structured scientific analysis software for GPS radio occultation data of the neutral atmosphere was developed for the CHAMP occultation analyses (Wickert 2002; Marquardt et al. 2001; Hocke 1997). The atmospheric excess phases are calculated for each occultation event (see Chap. 4.1) and the vertical profiles of refractivity, temperature and water vapor are derived (see Chap. 4.2). The analysis modules are part of a dynamically configurable system for operational data product generation. The basics of such system are described by Wehrenpfennig et al. (2001). It ensures the continuous data flow through the scientific analysis modules and provides the interface for making available the input data and for the provision of the atmospheric data products to the archive system (see Fig. 4). Including scientific modules for ionosphere data analysis the system is also used for the operational analysis of CHAMP's ionospheric occultations (Jakowski et al. 2003, $2002 \mathrm{~b}$ ). These data products may be used to derive space weather information on the global state of the ionosphere (Jakowski et al. 2001; Wehrenpfennig et al. 2001).

Apart from the reliability and robustness of the operational occultation processing system, the reliability and the timeliness for providing the input data is the crucial factor for a continuous and rapid product delivery. These are (we focus here to the neutral atmosphere): CHAMP's GPS measurements, the fiducial network data and the precise orbit ephemeris of CHAMP and the GPS satellites.

The first requirement is the continuous availability of CHAMP's GPS data for the precise orbit determination $(1 / 10 \mathrm{~Hz}$ phases and pseudoranges) and occultation processing $(50 \mathrm{~Hz}$ phases). This is achieved by using the nearpolar receiving station at $\mathrm{Ny}$ Ålesund. A ground contact occurs about every $86 \mathrm{~min}$ with a minimum duration of $\sim 7$ min (simulation study by Wickert et al. 2001b). The time delay due to the 


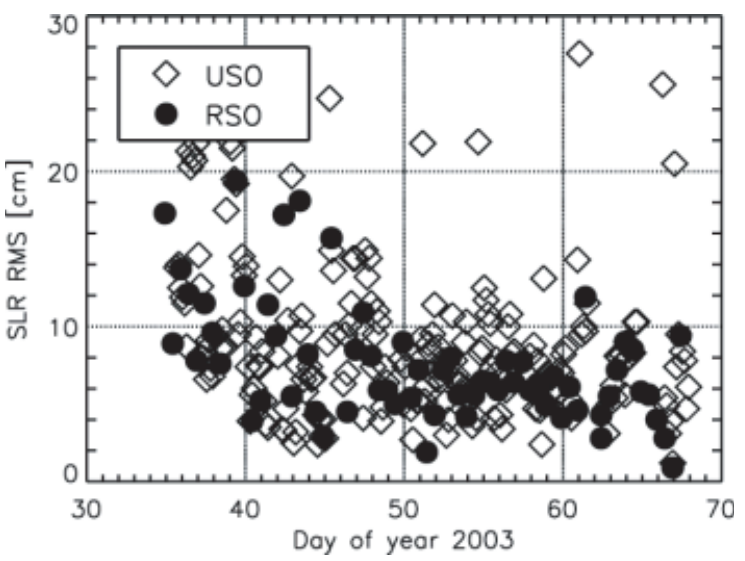

Fig. 5. Comparison of Satellite Laser Ranging (SLR) residuals (3D) for Rapid Science Orbits (RSO) and Ultra rapid Science Orbits (USO) for the CHAMP satellite, derived by GFZ's precise orbit determination facility for the period between February 3 (Doy 34) and March 7 (Doy 67), 2003. The accuracy of both orbit products is comparable (Average SLR residual for $\mathrm{RSO} 7.6 \mathrm{~cm}$; for USO $9.8 \mathrm{~cm}$ ).
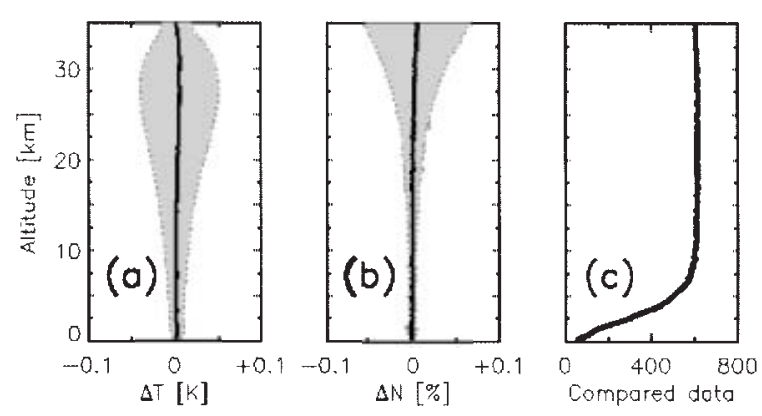

Fig. 6. Comparison of two sets of 614 vertical a) dry temperature and b) refractivity profiles, derived from CHAMP occultation measurements during February 4-8, 2003 (doy 36-40). The profiles are derived using USO and RSO respectively. The comparison indicates 2 nearly identical data sets with no remarkable mean deviation in temperature and refractivity up to $35 \mathrm{~km}$ and negligible standard deviation of $<0.05 \mathrm{~K}(\mathrm{~T})$ and $0.05 \%(\mathrm{~N})$ over the entire height interval. The average delay between measurement and data provision was $\sim 5$ hours for each USO profile. The number of compared data vs. height is shown in c). data transfer to the processing center at GFZ can be neglected.

The time delay for providing the ground station data (hourly RINEX files) via CHAMP's ISDC is currently between 30 to $70 \mathrm{~min}$. The delay can be further reduced since the data are transmitted from the ground station sites as files covering $15 \mathrm{~min}$ intervals. These files are transferred to the network processing centers with maximum time delay of 15 min (Wickert et al. 2004; Galas et al. 2001).

The described operational availability of the GPS satellite and ground data with low latency allows for the demonstration of rapid orbit and occultation processing. Since April 2002 the GPS and CHAMP satellite orbit ephemeris are available about every 3 hours (Ultra rapid Science Orbit, USO; König et al. 2003). The USO data cover a $14 \mathrm{~h}$ (CHAMP) and $24 \mathrm{~h}$ (GPS) time window, respectively, up to $\sim 3 \mathrm{~h}$ before delivery. The accuracy of the USO is comparable to the CHAMP standard product, the Rapid Science Orbit (RSO), which is delivered on a daily basis with $\sim 24$ hours latency (König et al. 2002). Satellite Laser Ranging (SLR, 3D) residuals for CHAMP USO and RSO are shown in Fig. 5 (average deviation for RSO: $7.6 \mathrm{~cm}$; for USO: $9.8 \mathrm{~cm}$ ). The average RMS of the difference to IGR orbit solution (provided by the IGS) of the GPS satellites is $\sim 8 \mathrm{~cm}$ for the RSO and $\sim 12 \mathrm{~cm}$ for the USO. The slight difference in the accuracy between USO and RSO data can be attributed to the difference in the distribution of GPS ground data which naturally becomes better with time passed away.

Due to the availability of USO the demonstration of Near-Real-Time provision of precise GPS occultation data products became feasible and is demonstrated at GFZ since April 2002. The accuracy of the Near-RealTime products is shown in Fig. 6. The comparison of two sets of each 614 vertical temperature profiles, one processed using RSO (GPS and CHAMP orbits), the other using USO, yields no discernible difference. The mean deviation of the dry temperature and the refractivity is almost zero, the standard deviation is negligible $(<0.05 \mathrm{~K} ;<0.05 \%)$ within the entire height interval. The decrease in the standard deviation of the temperature 


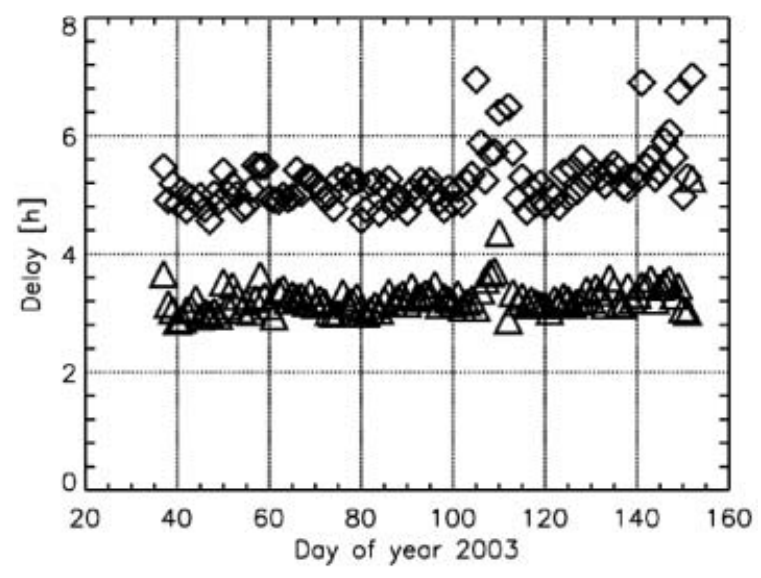

Fig. 7. Time delay between CHAMP occultation measurements and availability of analysis results at GFZ during February until May 2003. Diamonds indicate the daily mean of the time delay between measurement and availability of calibrated atmospheric excess phases for all occultation events. An average of $\sim 5$ hours for the entire period is reached. The minimum time delays are marked by triangles. On 10 days (out of 116) at least one excess phase reached the 3 hour limit between measurement and provision. A minimum delay of $2: 52 \mathrm{~h}$ was reached on February 9 (Doy 40), 2003.

profiles at altitudes above $\sim 30 \mathrm{~km}$ is due to the initialization of the hydrostatic equation at $43 \mathrm{~km}$ with identical values (ECMWF data) for USO and RSO profiles (see Chap. 4.2). For each of the USO profiles a delay between measurement and provision of the temperature profile of $\sim 5$ hours was reached (Fig. 7). The RSO profiles are generated with $\sim 16$ hours latency in relation to the measurement. We note that the real delay between measurement and data provision of vertical temperature and humidity profiles is enhanced by the need of independent meteorological data (global weather analyses from ECMWF) for the quality control. This results in a total delay of $\sim 1-2$ days between measurement and provision of the profiles at the ISDC. Using global weather forecasts instead of the analyses this delay can be further reduced.

However, the meteorological research over the past years has concentrated on the eval- uation of assimilation of the ionosphere free bending angles or refractivity profiles (Kuo et al. 2000; Eyre 1994) instead of vertical temperature and/or water vapor profiles. Bending angles and refractivity can be directly derived from the atmospheric excess phase (see e.g., Kursinski et al. 1997), which is provided as an result of the Near-Real-Time data analysis, without ancillary meteorological data.

For that reason the Near-Real-Time generated atmospheric excess phases are provided to the Max-Planck-Institute for Meteorology (MPI, development of assimilation techniques for the German Weather Service as a project partner within GASP, see Chap. 1) since January 2003. Thus the delay for continuous data provision can be investigated under realistic conditions. The time differences between occultation and arrival of the excess phases at MPI are automatically recorded and analysed since February 2003. Fig. 7 shows the result of an initial statistic analysis of more than 100 days Near-Real-Time processing of CHAMP occultation data. The mean latency of all analysed excess phases for the entire period was $\sim 5 \mathrm{~h}$. On each day the minimum delay is on the order of 3 hours. On 10 days events reached a delay of less than 3 hours. This result is very encouraging for a future operational use of GPS radio occultation data in NWP, since the timeliness achieved, in part already match the latency requirement for global NWP (see Chap. 1). Due to the transmission of 15 min ground station files every $15 \mathrm{~min}$, a further reduction of the time interval for the provision of the precise orbits (USO currently $3 \mathrm{~h}$ ) and consequently of the average $5 \mathrm{~h}$ latency for the atmospheric data products will be feasible.

\section{Validation of vertical atmospheric profiles}

The period after the flight-receiver software update on March 10, 2002 up to the end of the year (see Fig. 1) was used for a validation study to evaluate the quality of the CHAMP profiles. 46,000 measurements (GO) were available for the comparisons (all results of the operational data analysis during this period). In contrast to Marquardt et al. (2003) or Wickert et al. (2001b) we validate the current version of atmospheric data products (004), which is available via ISDC. In addition we present valida- 

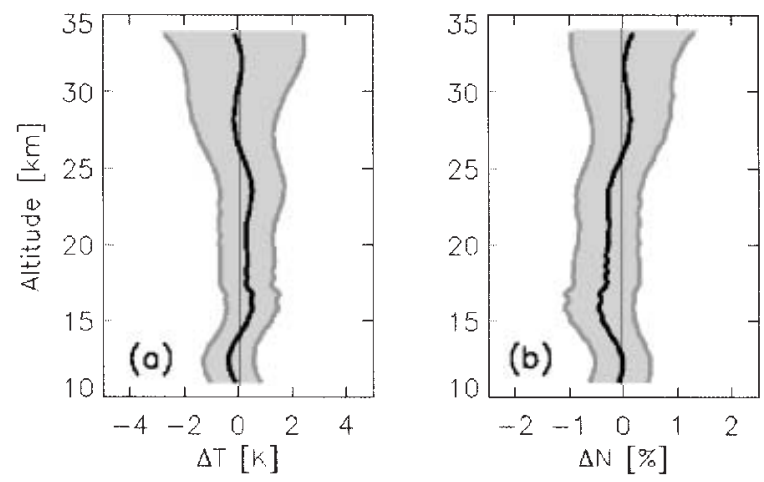

Fig. 8. Statistical comparison between 46,300 vertical a) temperature and b) refractivity profiles from CHAMP (GO) and corresponding ECMWF analysis data (CHAMP-ECMWF).

tion results of a set of 32,196 measurements, analysed using the CTss method. This analysis technique is still not used for the operational data processing. Despite of the fact, that GO and CTss data set consist of a different number of profiles, the validation results can be directly compared. We've found that subsets of the GO data set (e.g., corresponding with the 32,196 CTss profiles) show statistically nearly identical behaviour as the complete set.

\subsection{Upper troposphere/Stratosphere}

The comparison of CHAMP dry temperature and refractivity profiles with interpolated data from 6-hourly operational meteorological analyses from ECMWF is shown in Fig. 8. Between 10 and $35 \mathrm{~km}$ the bias is $<0.5 \mathrm{~K}$, the mean deviation of the refractivity is $<0.5 \%$. A height dependent standard deviation of $\sim 1 \mathrm{~K}(\sim 0.6 \%)$ at $10 \mathrm{~km}$ and $\sim 2 \mathrm{~K}(\sim 1 \%)$ at $30 \mathrm{~km}$ is observed in the temperature and refractivity comparison, respectively. We note, that the refractivity profiles were derived without ancillary meteorological data. A climatology (MSISE-90, see Chap. 4.2) was used for optimizing the bending angles above $\sim 30 / 40 \mathrm{~km}$.

A validation study using data of the global radiosonde (RS) network confirms this result (Fig. 9). The comparison was performed at the standard pressure levels. For 5,843 out of the 46,300 CHAMP occultations exist a corresponding radiosonde measurement with a distance $\Delta d$ of less than $300 \mathrm{~km}$ and a time difference $\Delta t$ of $<3 \mathrm{~h} .129$ of these sounding satisfy the
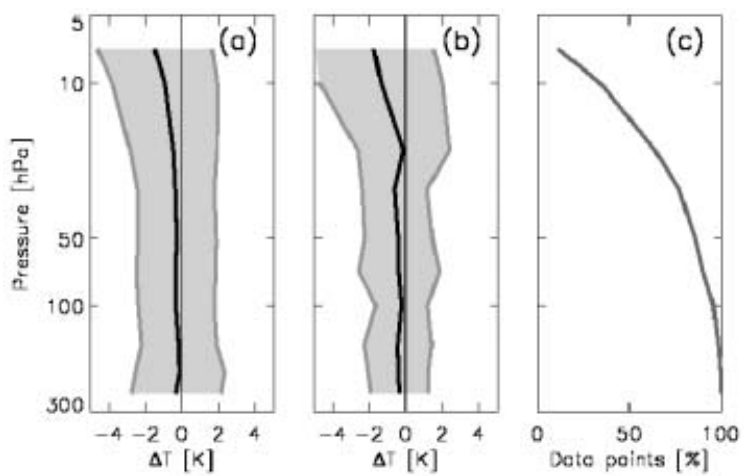

Fig. 9. Statistical comparison of CHAMP dry temperatures (GO) with radiosonde (RS) data (CHAMP-RS); a) 5,843 soundings $\Delta t<3 \mathrm{~h}, \quad \Delta d<300 \mathrm{~km}$; b) 129 soundings $\Delta t<1 \mathrm{~h}, \Delta d<100 \mathrm{~km} ; \mathrm{c})$ approximate height dependent percentage of radiosonde data available for the comparisons a) and b).

$\Delta d<100 \mathrm{~km}$ and $\Delta t<1 \mathrm{~h}$ criteria. The data sets exhibit nearly no bias between $300 \mathrm{hPa}$ ( $\sim 9 \mathrm{~km}$ altitude) and about $20 \mathrm{hPa}(\sim 27 \mathrm{~km})$ standard pressure level. Above $20 \mathrm{hPa}$ a cold bias of the CHAMP retrievals is observed, reaching $\sim 2 \mathrm{~K}$ at $7 \mathrm{hPa}(\sim 33 \mathrm{~km})$ for both comparisons. Between $300 \mathrm{hPa}$ and $\sim 20 \mathrm{hPa}$ a clear reduction of the standard deviation between the CHAMP and RS data from $\sim 2 \mathrm{~K}$ in the $300 \mathrm{~km} / 3 \mathrm{~h}$ comparison to $\sim 1-1.5 \mathrm{~K}$ in the $100 \mathrm{~km} / 1 \mathrm{~h}$ is detected.

Between 10 and $25 \mathrm{~km}(\sim 25 \mathrm{hPa})$ the temperature bias in relation to the analyses (especially around $15 \mathrm{~km}$, the location of the tropical tropopause region) seems to be slightly larger than in relation to the radiosonde data, which can be an indicator for deviations of the analyses from the real atmospheric situations. The slightly negative bias of the CHAMP measurements of $\sim 0.3 \%$ in relation to the analyses, observed between 12 and $25 \mathrm{~km}$ may confirm this assumption. A more detailed analyses of the observed biases however is beyond the scope of our study.

\subsection{Lower troposphere}

Fig. 10a shows a comparison of tropospheric refractivities derived using the geometrical optics (GO) approximation. A total of 46,300 occultations are included. The data are sorted in latitude bins of $5^{\circ}$ and altitude bins of $0.2 \mathrm{~km}$. 
Below $6 \mathrm{~km}$ a negative refractivity bias of CHAMP data in relation to the analyses is observed. The bias is most pronounced in the Tropics and reaches here $\sim 5 \%$ below $2 \mathrm{~km}$, up to $\sim 7 \%$ in the last $\mathrm{km}$ above Earth's surface between 0 and $30^{\circ}$ South. It extends to midlatitudes, where it decreases down to $\sim 1 \%$ at $60^{\circ} \mathrm{N}$. These features are almost identical with the findings of Ao et al. (2003). The authors characterized the bias and discussed in detail its origins. These are: non-correct treatment of multipath effects in the lower troposphere (e.g., Gorbunov 2002), the GPS receiver tracking of signals propagating the lower troposphere (Ao et al. 2003; Beyerle et al. 2003a) and problems related to critical refraction (e.g., Sokolovskiy 2003). The application of the CTss method (see Chap. 4.2) significantly reduces the observed bias (Fig. 10b). A bias of less then $\sim 0.5 \%$ is observed nearly down to Earth's surface for profiles $>45^{\circ}$ North and South. Even in the tropics the bias does not exceed $-1.5 \%$ above $2 \mathrm{~km}$. However below $2 \mathrm{~km}$ (region of the planetary boundary layer) in the Tropics $\left(30^{\circ} \mathrm{S}\right.$ up to $30^{\circ} \mathrm{N}$ ) negative biases in the CHAMP retrieval occur (up to $\sim 4 \%$ for small meridional regions).

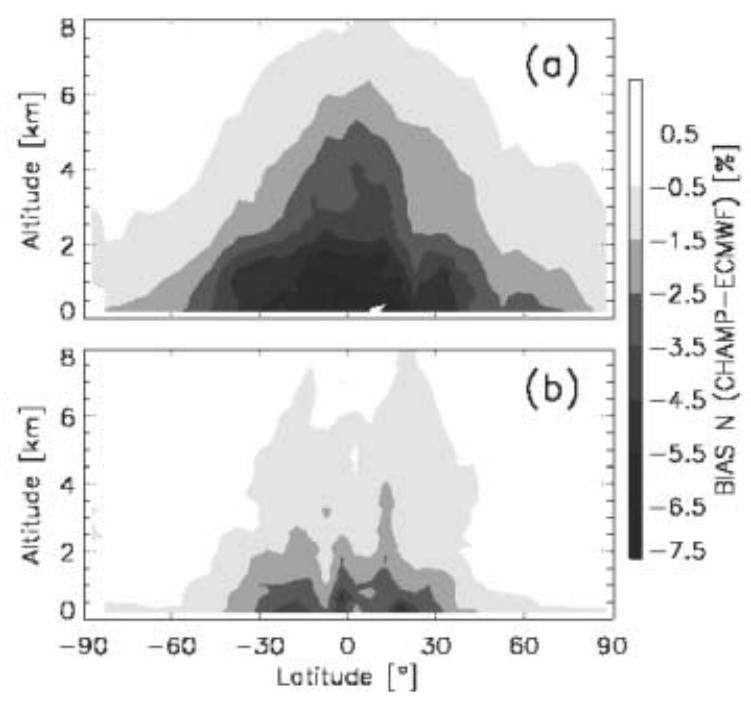

Fig. 10. Meridional distribution of the mean fractional refractivity difference between 46,300 CHAMP retrievals (2002) derived (a) using the geometrical optics approximation and (b) applying the CTss analysis technique and corresponding ECMWF analyses data.
Improvements in the receiver software (data wipeoff, implementation of open-loop tracking) will help to reduce the bias in the near future (e.g., Beyerle et al. 2003a). However the ducting (problems associated with strong refractivity gradients at the top of the planetary boundary layer at $1-2 \mathrm{~km}$ altitude) is a fundamental limitation of the RO method (see e.g., Ao et al. 2003; Engeln et al. 2003 or Sokolovskiy 2003).

\subsection{Specific humidity}

The operational occultation processing system also provides vertical profiles of specific humidity (see Chap. 4.2). The observed negative refractivity biases (see Chap. 7.2) should directly map to dry biases in the derived water vapor profiles. Variational retrieval schemes, combining measurement and background, taking into account their errors characteristics, are more promising to derive specific humidity, but also suffer from the observed bias in refractivity. The suitability of these methods for operational use is still not satisfactory tested, but they will be implemented in the operational CHAMP processing in near future. For this purpose an algorithm, developed by of Healy and Eyre (2000), is foreseen. Here, we evaluate the specific humidity, derived using the standard method (Chap. 4.2).

For both refractivity data sets $(46,300$ GO and 32,196 CTss profiles) used in Chap. 7.2 vertical profiles of specific humidity were derived (see Chap. 4.2). The data are sorted in latitude bins of $5^{\circ}$ and altitude bins of $0.2 \mathrm{~km}$, negative values of the specific humidity are excluded from the comparison. In case of GO approximation the derived water vapor profiles exhibit in the statistical mean unacceptable large biases, reaching up to $30-40 \%$ in the Southern Tropic region even below $5 \mathrm{~km}$ (Fig. 11a). The situation is significantly improved if the CTss refractivity profiles are used for the derivation of humidity (Fig. 11b). The dry bias of the water vapor retrievals in relation to ECMWF is reduced by about an factor of 3 . Biases larger than $-15 \%$ are observed only in the tropic region below $\sim 1 \mathrm{~km}$ and in the upper troposphere, where very small absolute values of specific humidity of $\sim 0.02-0.05 \mathrm{~g} / \mathrm{kg}$ are observed. We conclude that the improvement of the refractivity retrieval (see Chap. 7.2) is the 


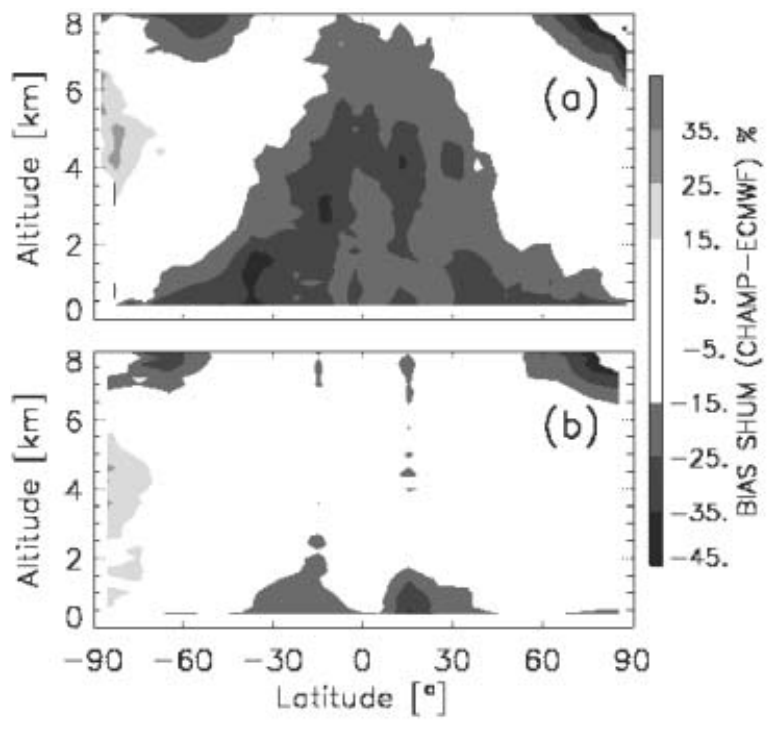

Fig. 11. Meridional distribution of the mean specific humidity difference between CHAMP retrievals and corresponding ECMWF analyses data for 2002. The profiles are derived using (a) geometrical optics approximation (46,300 profiles) and (b) CTss method for the refractivity retrieval $(32,196)$.

key issue for the derivation of precise water vapor profiles from GPS radio occultation measurements.

This is confirmed by a statistical comparison of CHAMP profiles with corresponding radiosonde data (Fig. 12). A set of 3,724 vertical refractivity and humidity profiles, derived from CHAMP occultation measurements (recorded between March 10 and December 31, 2002) using GO approach and CTss method (comparison, if both, CTss and GO profile, were available) respectively was compared with corresponding radiosonde data. About $69 \%$ of the compared data are located at latitudes between $30^{\circ}$ and $70^{\circ} \mathrm{N}$. In good agreement with Fig. 10a negative refractivity bias reaching up to $\sim 2 \%$ in vicinity of the Earth's surface is observed in the GO retrievals. The standard deviation is about $3.5 \%$ there. The application of the CTss method reduces the bias significantly to $\sim 0.3 \%$ and the standard deviation to about $2.5 \%$. Bias and standard deviation of the specific humidity profiles are also signifycantly reduced below $500 \mathrm{hPa}$ from $\sim 0.7 \mathrm{~g} / \mathrm{kg}$ to $\sim 0.2 \mathrm{~g} / \mathrm{kg}$ (dry bias)

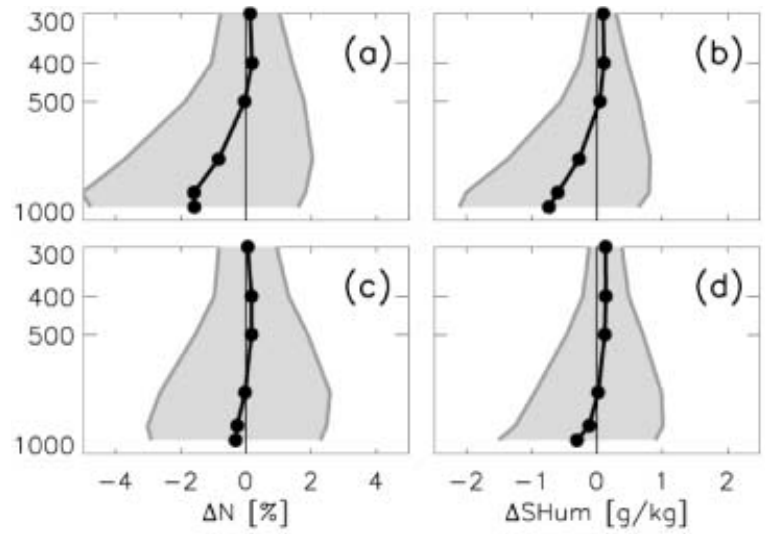

Fig. 12. Statistical comparison of 3,724 CHAMP tropospheric refractivitiy (a,c) and specific humidity (b,d) profiles with radiosonde (RS) data (CHAMP-RS); $\mathrm{a}, \mathrm{b}$ ) derived using GO approximation; c,d) applying the CTss method $(\Delta t<3 \mathrm{~h}$, $\Delta d<300 \mathrm{~km}$ ).

and $\sim 1.5 \mathrm{~g} / \mathrm{kg}$ to $\sim 1.0 \mathrm{~g} / \mathrm{kg}$ (standard deviation) by applying the CTss method. We note, that we've excluded unphysical values for the CHAMP water vapor (negative) from the comparison. These values can be observed if large negative biases in the refractivity profiles exist, which are used for the water vapor derivation. We've used this as additional quality criterion, the statistics was not significantly modified.

\subsection{Validation of vertical electron density profiles}

The achievable accuracy of the electron density profiles depends on various factors and cannot be discussed here in detail. One of these factors is e.g., the assumption of spherical symmetry (see Chap. 4.3). To get an estimate of the accuracy of the derived profiles, the F2 layer critical frequency foF2 and the corresponding height hmF2 were extracted from the profile data and compared with observational values (ionosonde data) taken from the SPIDR data base (O'Loughlin 1997). The comparison was made for data that coincide within a spatial cross section of $8^{\circ}$ radius and within a time window of 30 minutes. The calculated absolute deviations of foF2 are shown in Fig. 13.

The absolute distribution function is biased by $0.18 \mathrm{MHz}$ and $13.4 \mathrm{~km}$ for foF2 and hmF2 


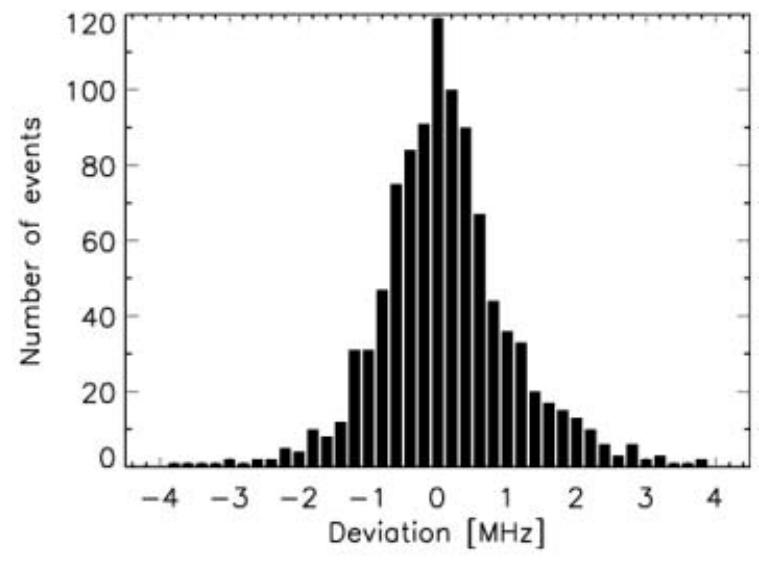

Fig. 13. Comparison of IRO derived foF2 values and corresponding vertical sounding data taken from the SPIDR data bank (O'Loughlin 1997). The data of 1,006 vertical corresponding profiles, recorded during April 11, 2001 and June 30, 2002, were compared [mean bias: $0.18 \mathrm{MHz}$; dispersion (RMS): $1.28 \mathrm{MHz}]$.

respectively. Whereas the bias for the critical frequency of $0.18 \mathrm{MHz}(\mathrm{RMS}=1.28 \mathrm{MHz})$ is rather small, bias and dispersion of the peak density height of $13.6 \mathrm{~km}(\mathrm{RMS}=46.8 \mathrm{~km})$ are surprisingly big and therefore needs further discussion. The results are in principal agreement with previous studies (Jakowski et al. 2002b, 2003).

To evaluate the accuracy of the entire profile from the CHAMP orbit height down to the $\mathrm{E}$ layer, IRO data were compared with vertical sounding data of selected mid-latitude stations. Preliminary results indicate a small positive bias of the IRO data in the order of about $0.5 \mathrm{MHz}$ and a standard deviation from the mean of about $1 \mathrm{MHz}$ throughout the entire profile. Considering the large spatial and temporal cross section the agreement is quite well.

\section{Provision of GPS occultation data and analysis results via the Information System and Data Center}

GPS occultation data from CHAMP, ground station data, satellite ephemeris and results of the operational data analysis (see Table 1) are provided via the CHAMP's data center, ISDC, (http://isdc.gfz-potsdam.de/champ/). De-
Table 1. Overview of available GPS occultation data and products at the CHAMP data center (ISDC) at GFZ Potsdam (http://isdc.gfz-potsdam.de/ champ/).

\begin{tabular}{|l|l|}
\hline Data product & \multicolumn{1}{|c|}{ Brief explanation } \\
\hline CH-AI-1-HR & $\begin{array}{l}\text { Occultation measurements from } \\
\text { CHAMP }\end{array}$ \\
\hline CH-AI-1-FID & Fiducial network data \\
\hline CH-AI-2-TAB & List of daily occultation events \\
\hline CH-AI-2-PD & $\begin{array}{l}\text { Atmospheric excess phase for } \\
\text { each occultation event }\end{array}$ \\
\hline CH-AI-3-ATM & $\begin{array}{l}\text { Vertical atmospheric profile } \\
\text { (dry atmosphere assumed) }\end{array}$ \\
\hline CH-AI-3-WVP & Water vapor profile \\
\hline CH-AI-3-TCR & Relative TEC data \\
\hline CH-AI-3-IVP & Electron density profiles \\
\hline CH-OG-3-RSO & $\begin{array}{l}\text { Rapid Science Orbit data for } \\
\text { CHAMP and GPS satellites }\end{array}$ \\
\hline
\end{tabular}

tailed Information regarding the current status of CHAMP's occultation experiment and the Near-Real-Time data analysis can be found at the GASP homepage: http://www.gfz-potsdam. de/gasp.

Recently, results of the improved data processing (see Chap. 4.2, product version 004) are provided. In a next step GPS flight-software modifications in combination with the implementation of the CTss method (Chap. 7.2 and 7.3) will further increase the accuracy of the atmospheric data products.

In addition to these improvements the provision of a new data product type is foreseen in near future: results of a 1Dvar data analysis (CH-AI-3-VAR, implementation of the algorithm described by Healy and Eyre, 2000). This method is based on optimal estimation of both, temperature and humidity. The measured refractivity profile is combined with a priori data (derived from ECMWF analyses) taking into account the error characteristics in a "statistic optimal" way.

\section{Summary and Outlook}

About five years after GPS/MET the CHAMP experiment not only succeeded this pioneering 
mission; CHAMP also brought significant progress for the GPS radio occultation technique. Due to improved GPS receiver technique (JPL's state-of-the-art flight receiver "BlackJack") and the operational operated occultation infrastructure CHAMP allows for continuous atmospheric sounding independent of the AntiSpoofing mode of the GPS. The CHAMP data (neutral atmospheric and ionospheric occultations) are automatically processed, the analysis results are provided to the scientific community via the CHAMP data center, ISDC, at GFZ (http://isdc.gfz-potsdam.de).

Using a near-polar receiving station at $\mathrm{Ny}$ Ålesund, Spitsbergen and the data of the global "High Rate and Low Latency GPS ground network" for the first time rapid orbit and occultation processing (Near-Real-Time) is continuously demonstrated. An average delay between measurement and provision of analysis results for assimilation purpose of $\sim 5$ hours is continuously reached, for single occultations a delays of shorter than 3 hours after measurement is observed. A further reduction of the average delay is possible. It was shown that the rapid processing using ultra rapid orbit solutions provides almost identical results in relation to the standard processing. The operational data processing and continuous provision of analysis results allows for the first time for validation studies using several tens of thousands vertical profiles of refractivity, temperature and water vapor to characterize the accuracy of the operational data products. For this purpose a validation study was performed using more than 46,000 CHAMP profiles, recorded between March and December 2002. The profiles were compared with meteorological analyses from ECMWF and $\sim 6,000$ radiosonde measurements. The mean temperature bias in relation to the analyses is less then $0.4 \mathrm{~K}$ between 10 and $35 \mathrm{~km}$, the mean deviation of the refractivity is $<0.5 \%$. A height dependent standard deviation of $\sim 1 \mathrm{~K}$ at $10 \mathrm{~km}$ and $\sim 2 \mathrm{~K}$ at $30 \mathrm{~km}$ is observed. A negative bias of the refractivity in relation to the analyses up to $5 \%$ in the tropic region is found in the lower troposphere. The application of the canonical transform sliding spectral analysis technique reduces the bias by about a factor of 2 . The derived water vapor profiles show unacceptable large dry bias in relation to the analysis, if GO refractivity profiles were used for the retrieval. The application of the CTss technique reduces the biases in average by about a factor of 3 . Similar values are observed when comparing a set of $\sim 4,000$ occultations with radiosonde data. It was shown that for mid-latitudes the observed bias was avoided almost completely, except the planetary boundary layer. It is concluded that further achievement in reducing the negative bias also will significantly improve the quality of the derived water vapor retrievals.

About 1,000 vertical profiles of electron density, derived from CHAMP measurements are compared with data from the global ionosonde network. The CHAMP data are biased by $0.18 \mathrm{MHz}$ and $13.4 \mathrm{~km}$ for foF2 and hmF2 respectively. Standard deviations of $1.28 \mathrm{MHz}$ and $46.8 \mathrm{~km}$ are observed respectively.

Since March 10, 2002 continuously 200 atmosphere and about 160 ionosphere profiles of good quality in average are provided. Since the CHAMP mission is currently expected to last until late 2007, an unprecedented long-term-set of GPS occultation data covering a duration of 6 years is expected. This will stimulate the activities to turn the GPS occultation technique from a promising to an established method for global sounding of Earth's atmosphere.

\section{Acknowledgements}

We thank all engineers, scientists and officers, whose contributed to the success of the CHAMP mission and made the GPS radio occultation experiment possible. We are grateful to R. Galas, L. Grunwaldt, W. Köhler and B. Ritschel for the handling of the GPS occultation and ground data. We acknowledge our colleagues from JPL, especially Tom Meehan, Tom Yunck, Toni Mannucci, George Hajj, Dave Stowers and Jim Zumberge for fruitful cooperation. We thank Chris Marquardt for his contribution to the analysis of the CHAMP data during the initial period of the occultation experiment, especially for his work to handle the ancillary meteorological data. We thank Kathrin Schöllhammer for the preparation of the radiosonde data. Our study was carried out in the GASP (GPS Atmosphere Sounding Project) strategy funds program under the grant of the German Federal Ministry of Education and Research (BMBF) no. 01SF9922/2. 


\section{References}

Anthes, R.A., C. Rocken, and Y.H. Kuo, 2000: Applications of COSMIC to Meteorology and Climate. Terrestrial, Atmospheric and Oceanic Sciences, 11, 115-156.

Ao, C.O., T.K. Meehan, G.A. Hajj, A.J. Mannucci, and G. Beyerle, 2003: Lower-Troposphere Refractivity Bias in GPS Occultation Retrievals. J. Geophys. Res., 108, 4577, doi:10.1029/ 2002JD003216.

Beyerle, G., M.E. Gorbunov, and C.O. Ao, 2003a: Simulation studies of GPS radio occultation measurements. Radio Sci., 38, 1084, doi:10.1029/2002RS002800.

-, J. Wickert, T. Schmidt, and Ch. Reigber, 2003b: Atmospheric sounding by GNSS radio occultation: An analysis of the negative refractivity bias using CHAMP observations. J. Geophys. Res., doi:10.1029/2003JD003922, in print.

Engeln von, A., G. Nedoluha, and J. Teixeira, 2003: An analysis of the frequency and distribution of ducting events in simulated radio occultation measurements based on ECMWF field, J. Geophys. Res., 108, 4669, doi:10.1029/ 2002JD003170.

Eyre, J.R., 1994: Assimilation of radio occultation measurements into a numerical weather prediction system, ECMWF, Tech. Memorandum No. 199.

Galas, R., J. Wickert, and W. Burghardt, 2001: High rate low latency GPS Ground Tracking Network for CHAMP. Phys. Chem. Earth (A), 26, 649-652.

Gorbunov, M.E., 2002: Canonical transform method for processing radio occultation data in the lower troposphere. Radio Sci., 37, 1076, doi:10.1029/2000RS002592.

and S.V. Sokolovskiy, 1993: Remote sensing of refractivity from space for global observations of atmospheric parameters. MaxPlanck-Institut für Meteorologie, Report 119.

Hajj, G.A., C.O. Ao, B.A. Iijima, D. Kuang, E.R. Kursinski, A.J. Mannucci, T.K. Meehan, L.J. Romans, M. de la Torre Juárez, and T.P. Yunck, 2003: CHAMP and SAC-C atmospheric occultation results and intercomparisons. J. Geophys. Res., (submitted).

— E.R. Kursinski, L.J. Romans, W.I. Bertiger, and S.S. Leroy, 2002: A Technical Description of Atmospheric Sounding by GPS Occultations. $J$. of Atmosphere. and Solar-Terrestrial Physics, 64, 451-469.

- L.C. Lee, X. Pi, L.J. Romans, W.S. Schreiner, P.R. Straus, and C. Wang, 2000: COSMIC GPS Ionospheric Sensing and Space Weather. Ter- restrial, Atmospheric and Oceanic Science, 11, 235-272.

Healy, S.B. and J.R. Eyre, 2000: Retrieving temperature, water vapour and surface pressure information from refractive-index profiles derived by radio occultation data: A simulation study. Q. J. R. Meteorol. Soc., 126, 16611683.

Hedin, A.E., 1991: Extension of the MSIS thermosphere model into the middle and lower atmosphere. J. Geophys. Res., 96, 1159-1172.

Hocke, K., A.G. Pavelyev, O.I. Yakovlev, L. Barthes, and N. Jakowski, 1999: Radio occultation data analysis by the radioholografic method. J. Atmos. Terr. Phys., 61, 1169-1177.

- 1997: Inversion of GPS meteorology data, Annales Geophysicae, 15, 443-450.

Jakowski, N., A. Wehrenpfennig, S. Heise, Ch. Reigber, and H. Lühr, 2003: Status of Ionospheric Radio Occultation CHAMP Data Analysis and Validation of Higher Level Data Products, First CHAMP Mission Results for Gravity, Magnetic and Atmospheric Studies, 462-472.

, I.S. Kutiev, S. Heise, and A. Wehrenpfennig, 2002a: A topside ionosphere/plasmasphere model for operational applications, Proceedings of URSI XXVII General Assembly, 21742177.

, A. Wehrenpfennig, S. Heise, Ch. Reigber, H. Lühr, L. Grunwaldt, and T.K. Meehan, 2002b: GPS Radio Occultation Measurements of the Ionosphere from CHAMP: Early Results. Geophys. Res. Lett., 29, 1457, doi:10.1029/ $2001 G L 014364$.

— S. Heise, A. Wehrenpfennig, and S. Schlüter, 2001: TEC Monitoring by GPS-A Possible Contribution to Space Weather Monitoring. Phys. Chem. Earth (C), 26, 609-613.

_ 1999: Capabilities of radio occultation measurements onboard LEO satellites for ionospheric monitoring and research, Proceedings of 4th COST 251 Workshop 'The Impact of the Upper Atmosphere on Terrestrial and EarthSpace Communications', 116-121.

Kuo, Y.-H., S.V. Sokolovskiy, R.A. Anthes, and F. Vandenberghe, 2000: Assimilation of GPS radio occultation data for numerical weather predicition. Terrestrial, Atmospheric and Oceanic Sciences, 11, 157-186.

König, R., Ch. Reigber, G. Michalak, T. Schmidt, and J. Wickert, 2003: Ultra-rapid Orbits for CHAMP Atmosphere Profiling. Geophysical Research Abstracts. EGU joint assembly, EAE03-A-10426.

, S. Zhu, Ch. Reigber, K.-H. Neumayer, H. Meixner, R. Galas, G. Baustert, and P. 
Schwintzer, 2002: CHAMP Rapid Orbit Determination for GPS Atmospheric Limb Sounding. Adv. Space Res., 30, 289-293.

Kursinski, E.R., G.A. Hajj, J.T. Schofield, R.P. Linfield, and K.R. Hardy, 1997: Observing Earth's atmosphere with radio occultation measurements using the Global Positioning System. J. Geophys. Res., 102, 23429-23465.

Lemoine, F.G., S.C. Kenyon, J.K. Factor, R.G. Trimmer, N.K. Pavlis, D.S. Chinn, C.M. Cox, S.M. Klosko, S.B. Luthcke, M.H. Torrence, Y.M. Wang, R.G. Williamson, E.C. Pavlis, R.H. Rapp, and T.R. Olson, 1998: The development of the joint NASA GSFC and the National Imagery and Mapping Agency (NIMA) geopotential model EGM96. NASA, Technical Paper NASA / TP-1998-206861.

Marquardt, C., K. Labitzke, Ch. Reigber, T. Schmidt, and J. Wickert, 2001: An assessment of the quality of GPS/MET radio limb soundings during February 1997. Phys. Chem. Earth (A), 26, 125-130.

, K. Schöllhammer, G. Beyerle, T. Schmidt, J. Wickert, and Ch. Reigber, 2003: Validation and data quality of CHAMP radio occultation data, First CHAMP mission results for gravity, magnetic and atmospheric studies, 384-396.

Maus, S., M. Rother, R. Holme, H. Lühr, N. Olsen, and V. Haak, 2002: First scalar magnetic anomaly map from CHAMP satellite data indicates weak lithospheric field. Geophys. Res. Lett., 29, 1702, doi:10.1029/2001GL013685.

O'Loughlin, K.F., 1997: SPIDR on the Web: Space Physics Interactive Data Resource on-line analysis tool. Radio Sci., 32, 2021-2026.

Pavelyev, A.G., A.V. Volkov, A.I. Zakharov, S.A. Krutikh, and A.I. Kucherjavenkov, 1996: Bistatic radar as a tool for Earth investigation using small satellites. Acta Astronautica, 39, 721-730.

Reigber, Ch., et al., 2003a: CHAMP Project Site, (http://www.gfz-potsdam.de/champ). -, P. Schwintzer, H. Neumayer, F. Barthelmes, R. König, Ch. Förste, G. Balmino, R. Biancale, J.M. Lemoine, S. Loyer, S. Bruinsma, F. Perosanz, and T. Fayard, 2003b: The CHAMPOnly EIGEN-2 Earth Gravity Field Model. Adv. Space Research, in print.

—, et al., 1998: GPS Atmosphere Sounding-An innovative approach for the recovery of atmospheric parameters. HGF Strategy fund proposal.

Rocken, C., R. Anthes, M. Exner, D. Hunt, S. Sokolovskiy, R. Ware, M. Gorbunov, W. Schreiner, D. Feng, B. Hermann, Y.-H. Kuo, and X. Zou, 1997: Analysis and validation of GPS/MET data in the neutral atmosphere. J. Geophys. Res., 102, 29849-29866.

Schmidt, T., J. Wickert, C. Marquardt, G. Beyerle, Ch. Reigber, R. Galas, and R. König, 2003: GPS Radio occultation with CHAMP: An innovative remote sensing method of the atmosphere. Adv. Space Research, in print.

Schreiner, W.S., D.C. Hunt, C. Rocken, and S. Sokolovskiy, 1998: Precise GPS Data Processing for the GPS/MET Radio Occultation Mission at UCAR. Proceedings of the Institute of Navigation-Navigation 2000, 103-112.

Sokolovskiy, S.V., 2003: Effect of superrefraction on inversions of radio occultation signals in the lower troposphere. Radio Sci., 38, doi:10.1029/ 2002RS002728.

- 2001: Modeling and inverting radio occultation signals in the moist troposphere. Radio Sci., 36, 441-458.

, and D. Hunt, 1996: Statistical optimization approach for GPS/MET data inversion. URSI GPS / MET workshop.

Steiner, A.K., G. Kirchengast, and H.P. Ladreiter, 1999: Inversion, error analysis, and validation of GPS/MET occultation data. Ann. Geophysicae, 17, 122-138.

Ware, R., M. Exner, D. Feng, M. Gorbunov, K. Hardy, B. Herman, Y. Kuo, T. Meehan, W. Melbourne, C. Rocken, W. Schreiner, S. Sokolovskiy, F. Solheim, X. Zou, R. Anthes, S. Businger, and K. Trenberth, 1996: GPS sounding of the atmosphere from low earth orbit: Preliminary results. Bull. Am. Meteorol. Soc., 77, 1940.

Wehrenpfennig, A., N. Jakowski, and J. Wickert, 2001: A Dynamically Configurable System for Operational Processing of Space Weather Data. Phys. Chem. Earth (C), 26, 601-604.

Wickert, J., R. Galas, T. Schmidt, G. Beyerle, Ch. Reigber, Ch. Förste, and M. Ramatschi, 2004: Atmospheric sounding with CHAMP: GPS ground station data for occultation processing. Phys. Chem. Earth, (in print).

, G. Beyerle, T. Schmidt, C. Marquardt, R. König, L. Grunwaldt, and Ch. Reigber, 2003: GPS radio occultation with CHAMP, in First CHAMP mission results for gravity, magnetic and atmospheric studies, Springer-Verlag, 371-383.

, 2002: The CHAMP radio occultation experiment: Algorithms, Processing system, and First results (in German). GFZ Scientific Technical Report 02/07.

, G. Beyerle, G.A. Hajj, V. Schwieger, and Ch. Reigber, 2002: GPS radio occultation with CHAMP: Atmospheric profiling utilizing the space-based single difference technique. 
Geophys. Res. Lett., 29, 1187, doi:10.1029/ $2001 \mathrm{GL} 013982$.

, Ch. Reigber, G. Beyerle, R. König, C. Marquardt, T. Schmidt, L. Grunwaldt, R. Galas, T. Meehan, W. Melbourne, and K. Hocke, 2001a: Atmosphere sounding by GPS radio occultation: First results from CHAMP. Geophys. Res. Lett., 28, 3263-3266.

, R. Galas, G. Beyerle, R. König, and Ch. Reigber, 2001b: GPS ground station data for CHAMP radio occultation measurements. Phys. Chem. Earth (A), 26, 503-511. 